\title{
ВЫДЕЛЕНИЕ РЕДКОЗЕМЕЛЬНЫХ ЭЛЕМЕНТОВ ПРИ ПЕРЕРАБОТКЕ ЭСТОНСКИХ ФОСФОРИТОВ
}

С увеличением производства фосфорных удобрений обостряется необходимость комплексного использования фосфатного сырья, среди ценных примесных компонентов которого содержатся и редкоземельные элементы (РЗЭ).

В последние годы наблюдается устойчивый рост потребления промышленностью как индивидуальных Р3Э (особенно лантана, неодима, самария, европия), так и редкоземельного концентрата [1]. Мировое потребление лантаноидов составляет в настоящее время 30 тыс. т/год $\left[{ }^{2}\right]$, их распределение по отраслям промышленности, \%: катализ и химические производства - 44, стекло и керамика - 31, металлургия -22 , электроника и атомная энергетика - $3\left[{ }^{3}\right]$.

По содержанию и качественному составу РЗЭ природные фосфаты являются перспективным сырьевым источником, при этом наибольшего внимания заслуживают апатиты Хибинского и Новополтавского месторождений, в которых суммарное содержание РЗЭ достигает $0,6-2 \%\left[{ }^{4}\right]$.

Фосфориты Раквереского месторождения Эстонской ССР содержат, по нашим определениям, в сумме $0,12-0,22 \%$ оксидов Р3Э $\left(\mathrm{Ln}_{2} \mathrm{O}_{3}\right)$. По этому показателю они мало отличаются от фосфоритов других месторождений (напр., Марокко - 0,14-0,16; Алжир - 0,13-0,18; Флори-

Состав лантаноидов в фосфатном сырье некоторых месторождений, \% от суммы

\begin{tabular}{|c|c|c|c|c|c|}
\hline \multirow[b]{2}{*}{ Элементы } & \multirow{2}{*}{$\begin{array}{c}\text { Кольский } \\
\text { апатит }\end{array}$} & \multicolumn{4}{|c|}{ Фосфориты } \\
\hline & & Флориды & Марокко & Египта & Эстонии * \\
\hline Лантан & 25,1 & 31,4 & 21,8 & 24,7 & 13,0 \\
\hline Церий & 45,0 & 25,1 & 14,0 & 32,9 & 27,5 \\
\hline Празеодим & 3,9 & 0,3 & $-\quad 4,5$ & 4,0 & 3,0 \\
\hline Неодим & 14,0 & 14,7 & 30,4 & 21,4 & 16,5 \\
\hline Самарий & 1,6 & 0,3 & 5,2 & 3,5 & 3,5 \\
\hline Европий & 0,5 & 0,9 & 0,9 & 1,0 & 1,5 \\
\hline Гадолиний & 1,5 & 3,0 & 5,9 & 5,3 & 6,3 \\
\hline Тербий & 0,1 & 0,9 & 0,9 & 0,5 & 1,5 \\
\hline Диспрозий & 1,0 & 3,4 & 5,0 & 3,3 & 2,7 \\
\hline Гольмий & 0,1 & 0,9 & 1,6 & 0,3 & 0,9 \\
\hline Эрбий & 0,15 & 4,4 & 3,9 & 1,6 & 1,4 \\
\hline Тулий & 0,002 & 0,4 & 1,7 & - & 0,3 \\
\hline Иттербий & 0,08 & 1,7 & 3,7 & 1,3 & 1,2 \\
\hline Лютеций & - & 0,6 & 0,5 & 0,3 & - \\
\hline Иттрий & 4,3 & & & & 21,7 \\
\hline
\end{tabular}

* Данные для эстонского фосфорита получены масс-спектрометрическим анализом, выполненным в лаборатории аналитической химии Хельсинкского технического университета под руководством Л. Ниннистё и П. Аарнио. 
да $-0,06-0,3)$ и значительно уступают кольскому апатиту, в котором концентрируется до $0,8-1 \% \mathrm{Ln}_{2} \mathrm{O}_{3}$. В эстонских фосфоритах, как и в фосфатном сырье других месторождений (табл. 1, 2), присутствуют в качестве микропримесей практически все РЗЭ в концентрациях от 0,002 до 0,25 г/кг. Количественно преобладают лантаноиды цериевой подгруппы, что характерно для земной коры в целом.

таблица 2

Редкоземельные элементы в фосфатном сырье и осадке аммонизации, г/кг

\begin{tabular}{l|c|c|c|c|c|c|c|c|c|c|c|c|c|c}
\hline & $\mathrm{y}$ & $\mathrm{La}$ & $\mathrm{Ce}$ & $\mathrm{Pr}$ & $\mathrm{Nd}$ & $\mathrm{Sm}$ & $\mathrm{Eu}$ & $\mathrm{Gd}$ & $\mathrm{Tb}$ & $\mathrm{Dy}$ & $\mathrm{Ho}$ & $\mathrm{Er}$ & $\mathrm{Tm}$ & $\mathrm{yb}$ \\
\hline $\begin{array}{l}\text { Фосфорит- } \\
\text { ный кон- } \\
\text { центрат } \\
\begin{array}{l}\text { Осадок ам- } \\
\text { монизации }\end{array}\end{array}$ & 0,2 & 0,12 & 0,25 & 0,03 & 0,15 & 0,04 & 0,01 & 0,06 & 0,01 & 0,03 & 0,005 & 0,02 & 0,002 & 0,01 \\
\hline
\end{tabular}

Подтверждается также иттриеносность фосфатных минералов оболовых фосфоритов. Распределение лантаноидов в изученных нами образцах (рис. 1) мало отличается от среднего распределения Р3Э в фосфоритах - явно выражен цериевый максимум ( $230 \%$ от суммы РЗЭ), $13-17 \%$ приходится на лантан и неодим, $3-6 \%$ составляют празеодим, диспрозий, самарий и гадолиний.

Исследование различных вариантов кислотной переработки эстонских фосфоритов [5,6] показало, что распределение РЗЭ между жидкой и твердой фазами и, как следствие, возможность их извлечения определяются методами разложения фосфатного минерала. При вскрытии фосфорита серной кислотой с получением фосфорной кислоты Р3Э распределяются между жидкой и твердой фазами в соотношении 1:2 и более $60 \%$ их теряется с фосфогипсом.

Азотно-сульфатные способы переработки также характеризуются распределением Р3Э по фазам - в кислотную вытяжку переходит 60$65 \%$ Р $3 Э$, потери с фосфогипсом составляют $35-40 \%$.

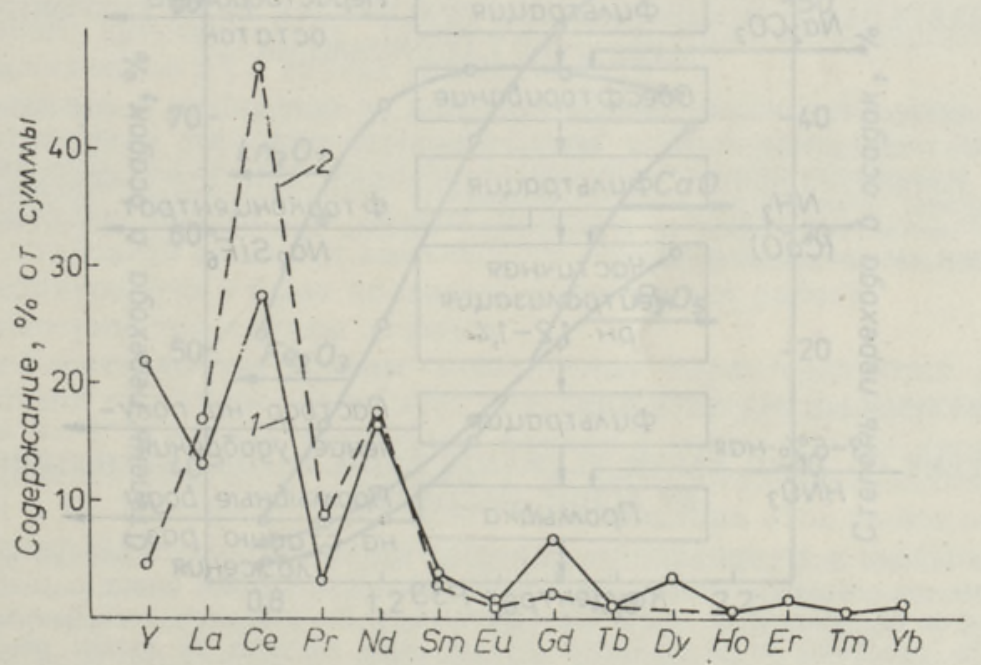

Рис. 1. Состав лантанондов в фосфоритном концентрате (1) и осадке аммонизации (2). 
При вскрытии фосфорита только азотной кислотой лантаноиды на 96-98\% переходят в раствор, откуда могут быть выделены в промежуточной стадии без существенного усложнения технологического процесса получения удобрения.

В настоящей работе изучены условия выделения РЗЭ осадительным методом из азотно-фосфатного раствора, полученного при разложении азотной кислотой пробы эстонского фосфорита следующего состава, \% : $\mathrm{P}_{2} \mathrm{O}_{5}-30,8, \mathrm{CaO}-47,5, \mathrm{MgO}-1,6, \mathrm{CO}_{2}-7,4, \mathrm{~F}-2,5$; полуторные оксиды 2,40 , в том числе $\mathrm{Fe}_{2} \mathrm{O}_{3}-1,81, \mathrm{Ln}_{2} \mathrm{O}_{3}-0,12$; нерастворимый остаток 5,6. Разложение фосфорита проводили при $60^{\circ} \mathrm{C}$ в течение 45 мин, количество азотной кислоты составляло $100 \%$ от стехиометрической нормы, рассчитанной по содержанию $\mathrm{CaO}$ в исходном сырье. После отделения нерастворимого остатка и обесфторивания вытяжки действием $\mathrm{Na}_{2} \mathrm{CO}_{3}$ содержание основных компонентов в растворе составляло, \%: $\mathrm{P}_{2} \mathrm{O}_{5}-8,5, \mathrm{CaO}-11,5, \mathrm{Fe}_{2} \mathrm{O}_{3}-0,24, \mathrm{Ln}_{2} \mathrm{O}_{3}-0,05$.

Выделение РЗЭ изучали путем частичной нейтрализации обесфторенного раствора оксидом кальция или газообразным аммиаком при температуре $70-90^{\circ} \mathrm{C}$ (схему см. на рис. 2). Опыты показали, что извлечение Р $3 Э$ и количество примесей в осадке определяются как степенью нейтрализации раствора, так и природой реагента-осадителя.

При нейтрализации обесфторенного раствора оксидом кальция степень извлечения РЗЭ в осадок ниже, чем с использованием аммиака, при тех же значениях рН раствора, и концентрат в большей степени загрязнен фосфатами кальция. Максимальная степень извлечения Р3Э $(67,6 \%)$

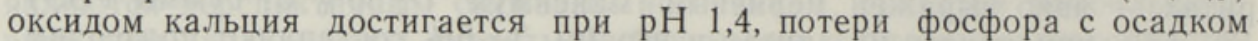
составляют при этом $14,5 \%$ от содержания $\mathrm{P}_{2} \mathrm{O}_{5}$ в исходном растворе. Известно, что количество фосфатов кальция, переходящих в осадок вместе с Р3Э, увеличивается с повышением содержания ионов кальция в растворе [7]. Применение извести для нейтрализации оказывается равнозначным использованию растворов с повышенной концентрацией ионов кальция и потому малоэффективно.

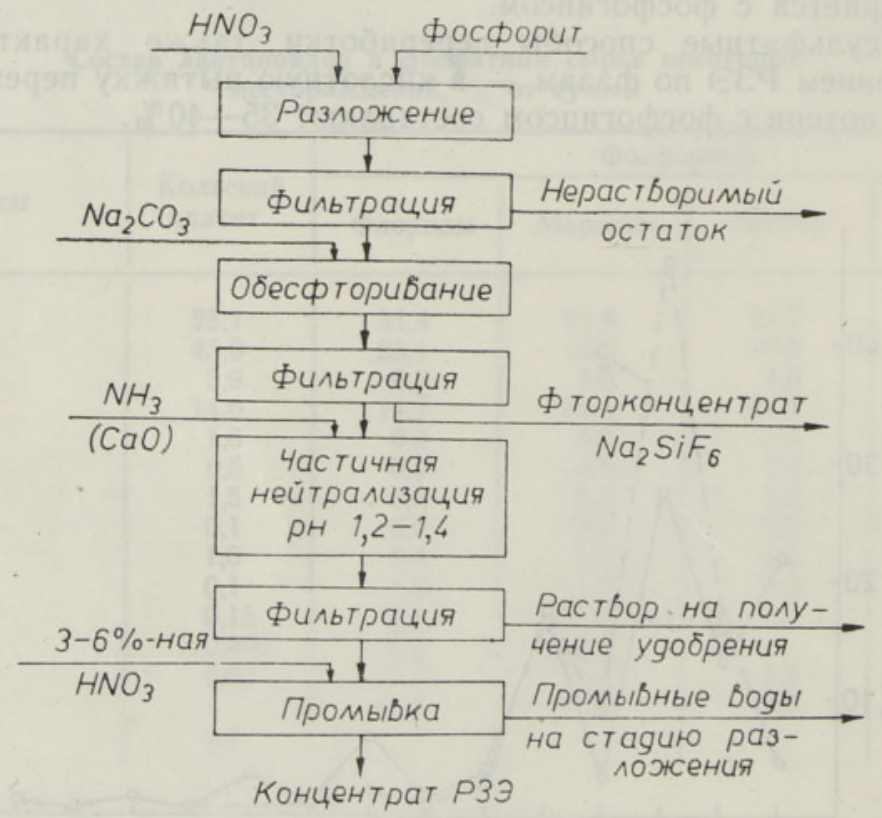

Рис. 2. Схема выделения редкоземельных элементов при азотнокислотной переработке эстонского фосфорита. 
Степень перехода основных компонентов в осадок при аммонизации изучали при $\mathrm{pH}$ от 0,8 до 2,2 (рис. 3 ). В этом интервале $\mathrm{pH}$ в твердую фазу переходят соединения железа, магния, алюминия, фосфаты РЗЭ, кальция и аммония. Осадок аммонизации содержит лантаноиды в виде гидратированных фосфатов типа $\mathrm{LnPO}_{4} \cdot \mathrm{H}_{2} \mathrm{O}$. Установлено присутствие комплексных соединений типа $(\mathrm{Fe}, \mathrm{Al}) \mathrm{NH}_{4}\left(\mathrm{HPO}_{4}\right)_{2} \cdot 0,5 \mathrm{H}_{2} \mathrm{O},(\mathrm{Fe}, \mathrm{Al}) \mathrm{Mg}$ $\left(\mathrm{NH}_{4}\right)_{2}\left(\mathrm{HPO}_{4}\right)_{2} \mathrm{~F}_{3}$, фосфатов $\mathrm{MgHPO}_{4}, \mathrm{NH}_{4} \mathrm{H}_{3} \mathrm{PO}_{4}, \mathrm{CaHPO}_{4}$ и сульфатов кальция, магния, аммония [8].

Масса осадка аммонизации резко увеличивается при повышении степени нейтрализации $(\mathrm{pH}>2)$, так как при этом наблюдается выпадение в осадок $\mathrm{CaHPO}_{4} \cdot \mathrm{H}_{2} \mathrm{O}$. Выделение Р3Э при изменении $\mathrm{pH}$ от 0,8 до 1,8 возрастает от 51 до $74 \%$, соединения железа переходят в осадок на $85-$ $90 \%$ (рис. 3 ), алюминия на $60-75 \%$, магния на $70-80 \%$ от содержания их в растворе.

В целях минимизации потерь фосфора при выделении Р3Э нейтрализацию обесфторенного раствора газообразным аммиаком следует проводить до $\mathrm{pH} \mathrm{1,2} \mathrm{(степень} \mathrm{нейтрализации} \mathrm{первого} \mathrm{водородного} \mathrm{иона}$ фосфорной кислоты не более $60 \%$ ), в этом случае степень осаждения Р3Э составляет $71 \%$, а потери фосфора с осадком - 7,2\% (рис. 3 ).

Концентрация почти всех легких лантаноидов в осадке аммонизации превышает в 20-30 раз их содержание в исходном концентрате (табл. 2), процентное распределение индивидуальных элементов от суммы практически сохраняется (рис. 1), содержание иттрия и некоторых тяжелых лантаноидов повышается в $3-5$ раз.

Суммарное содержание оксидов Р3Э в непромытом осадке аммонизации составляет $3-5 \%$, повышение концентрации основного вещества до $18 \%$ достигается путем многократной промывки осадка $3-6 \%$-ной азотной кислотой в результате селективного растворения фосфатов кальция и других примесей [ $\left.{ }^{9}\right]$. Возвращение промывного раствора в основной цикл производства удобрения снижает потери фосфора на стадии выделения РЗЭ.

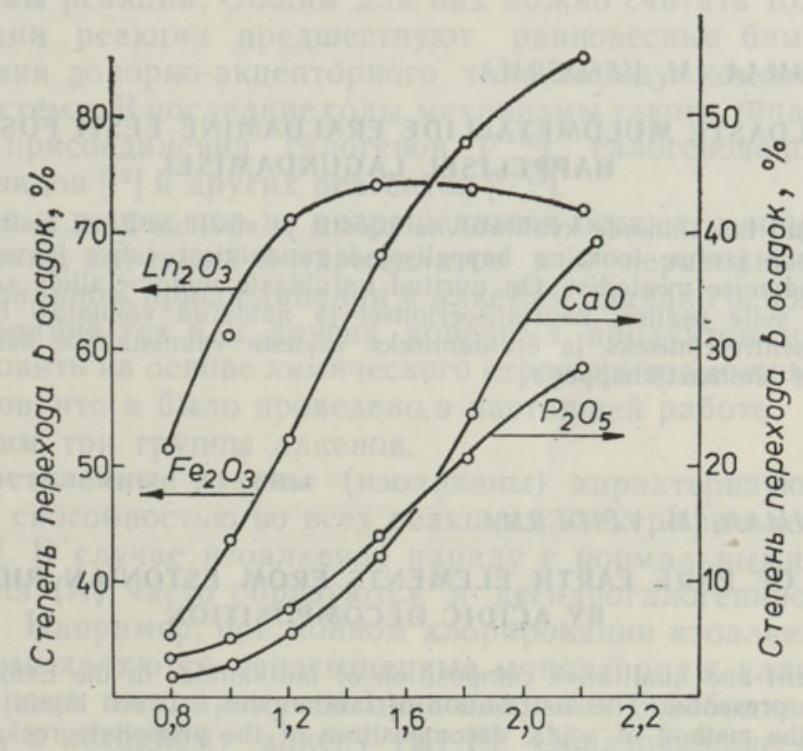

Рис 3. Влияние $\mathrm{pH}$ аммонизации на осаждение компонентов из раствора. 
Полученные данные дополняют комплексную характеристику фосфоритов Эстонии с учетом микроэлементного состава, показывают качественный состав лантаноидов, их межфазовое распределение, возможность концентрирования и извлечения при азотнокислотной переработке сырья на удобрения.

\section{Л ИТ Е Р А Т Р А}

1. Никонов В. Н., Михайличенко А. И., Афонин В. В., Норина Т. М. Об извлечении Р3М из апатита. - Науч. тр. Гиредмета, 1984, вып. 125, 67-71.

2. Habashi, F. The recovery of the lanthanides from phosphate rock. - J. Chem. Tech. Biotechnol., 1985, 35A, 5-14.

3. Nïnistö, $L$. Harvinaiset maametallit nykyaikaisen tekniikan palveluksessa. - Ann. Acad. Scient. Fennicae, vuosikirja $1983-84,207-213$.

4. Коган Б. И., Скрипка И. П. Об извлечнени РЗЭ из апатитов и фосфоритов. Редкие металлы. (Сырье и экономнка), вып. 8. М., 1973, 3-57.

5. Вийсимаа Л. П., Вейдерма М. А. Межфазовое распределение редкоземельных элементов при сернокислотной переработке эстонских фосфоритов. - В кн.: Тезисы докл. XII Всесоюзн. научно-техн. конф. «Технология неорганичческих веществ и минеральных удобрений», I. Чимкент, 1981, 256-258.

6. Вийсимаа Л. П., Треуфельдт О. Н. Межфазовое распределение редкоземельных элементов при азотнокислотном разложении фосфатного сырья. - Тр. Таллииск. политехн. ин-та, 1983 , № 542, 33-38.

7. Комплексная азотнокислотная переработка фосфатного сырья. Под ред. А. Л. Гольдинова и Б. А. Копылева. Л., 1982.

8. Евдокимова Л. И., Кононов А. В., Трутнева Н. В., Портнова Н. Л. Качественный и количественный состав осадков, образующихся при взаимодействии экстракционной фосфорной кислоты с аммиаком. Деп. ВИНИТИ $380-83.1983$.

9. Казак В. Г., Мельникова Н. С., Дмитриева В. С., Конюченко И. Н. Опытно-промышленная проверка технологии извлечения редкоземельных элементов из апатитового концентрата. - Хим. технология, 1983, № 1 (122), 13-15.

таллинский политехнический институт

Поступила в редакцию 18/VII 1986

\section{Ludmilla VIISIMAA, M. VEIDERMA}

\section{HARULDASTE MULDMETALLIDE ERALDAMINE EESTI FOSFORIIDI HAPPELISEL LAGUNDAMISEL}

On määratud lantanoidide kvalitatiivne koostis ja sisaldus Eesti fosforiidikontsentraadis, samuti nende jaotus tooraine happelisel lagundamisel tahke ja vedela faasi vahel sõltuvalt lagundamise meetodist. On uuritud haruldaste muldmetallide sadestamist nitrofosfaatlahusest selle osalisel neutraliseerimisel ja näidatud vôimalusi haruldaste muldmetallide kontsentreerimiseks ja eraldamiseks väetiste valmistamise käigus fosfaattooraine töötlemisel lämmastikhappega.

\section{Ludmilla VIISIMAA, M. VEIDERMA}

\section{RECOVERY OF RARE EARTH ELEMENTS FROM ESTONIAN PHOSPHORITES BY ACIDIC DECOMPOSITION}

Total content and qualitative composition of lanthanides in the Estonian phosphorite concentrate are presented. The distribution of lanthanides between liquid and solid phases depending on the method of acidic decomposition of the phosphate rock has been established. The conditions of precipitation of rare earth elements by partial neutralisation of nitro-phosphate solution have been investigated. It is shown that the concentrating and the recovery of lanthanides can be achieved during the production of fertilizers from phosphate rock by treating it with $\mathrm{HNO}_{3}$. 